\title{
The platelet-derived growth factor receptor as a target for vascular endothelial growth factor-mediated anti-angiogenetic therapy in head and neck cancer
}

\author{
BIRGIT BRAN, GREGOR BRAN, KARL HÖRMANN and FRANK RIEDEL \\ Department of Otolaryngology, Head and Neck Surgery, \\ University Hospital Mannheim, D-68135 Mannheim, Germany
}

Received June 30, 2008; Accepted September 9, 2008

DOI: 10.3892/ijo_00000147

\begin{abstract}
Inhibition of angiogenesis by blocking angiogenic cytokines or their pathways has become a major target in experimental cancer therapies. This therapeutical approach requires a profound knowledge of growth factor profiles that contribute to tumor growth and progression. The respective knowledge is presently rather incomplete for head and neck squamous cell carcinomas (HNSCC). Therefore we studied the serum levels and expression of platelet-derived growth factor (PDGF) in HNSCC patients and in cell culture as well as the effect of a PDGF-receptor (PDGF-R) inhibition by Imatinib (Gleevec, STI571) on the secretion and expression activity of PDGF and vascular endothelial growth factor (VEGF) by postulating there is a correlation between the PDGF and VEGF networks. PDGF levels in patients with HNSCC, PDGF and VEGF secretion by HNSCC cells, were measured by ELISA, expression of PDGF and VEGF by RTPCR. We found significantly increased PDGF levels in HNSCC patients' sera as well as in HNSCC cell lines. Treatment of the cell lines with Imatinib, a partially selective PDGF-R inhibitor, resulted in reduced secretion of PDGF and VEGF. This inhibiting effect was also reflected on the expression level of VEGF. In conclusion, the present study confirms the crucial role of PDGF in HNSCC growth and strongly suggests a correlation between the PDGF/PDGF-R and VEGF/VEGF-R pathway networks in HNSCC. Although further studies must be performed for a more complete understanding of this interaction, a targeting therapy for the inhibition of PDGF-R tyrosine phosphorylation by Imatinib may be a promising strategy for future tumor therapy by autocrine and paracrine inhibition of tumor growth and angiogenesis, presumably through simultaneous downregulation of PDGF and VEGF.
\end{abstract}

Correspondence to: Dr Birgit Bran, University HNO-Klinik, Klinikum Theodor-Kutzer-Ufer, D-68135 Mannheim, Germany E-mail: birgit.bran@gmx.de

Key words: plateled-derived growth factor, vascular endothelial growth factor, angiogenesis, Imatinib (Gleevec, STI571), head and neck cancer

\section{Introduction}

Head and neck squamous cell carcinoma (HNSCC) is an aggressive epithelial malignancy known to be the most common neoplasm arising in the upper aerodigestive tract. Of all human cancers, HNSCC is the most distressing since the head and neck are sites of the most complex functional anatomy in the human body. In 2000, HNSCC was ranked as the eighth leading cause of cancer death worldwide. Approximately 481,100 new cases developed, and 320,000 persons succumbed to this disease (1). The overall five-year relative survival rate from HNSCC is generally less than $50 \%$ (2). Improved techniques in surgery, radiation and chemotherapy have increased the local control of HNSCC, but the poor five-year survival rate has remained unchanged for more than three decades (2). Chemotherapy is generally employed in advanced cases but the response rates average only $25-40 \%$ with overall survival being measured in months (3). Thus, it is imperative that new treatment modalities are developed to increase the long-term survival of patients with HNSCC.

Angiogenesis, the process leading to the formation of new blood vessels, plays a key role in the survival of cancer cells, in local tumor growth and in the development of distant metastasis (4). The intensity of angiogenesis has been shown to be increased in various human tumors, including HNSCC (5). The induction of tumor vascularization is regulated by a variety of angiogenic peptides released from tumor cells, macrophages and the extracellular matrix (6). These factors fulfil various functions, including endothelial cell migration, proliferation and capillary tubule formation (7). Many angiogenic factors have been identified including vascular endothelial growth factor (VEGF)(8). VEGF is a potent endothelial mitogen that activates the angiogenic switch in vivo and enhances vascular permeability (9). VEGF has been shown to increase tumor growth and angiogenesis in vivo in a nude mouse model (10). Enhanced expression of VEGF has been detected in a large variety of malignant human tumors including HNSCC (11-13). We previously demonstrated extended VEGF serum concentration in HNSCC patients compared with healthy controls (14). VEGF expression in HNSCC tumors strongly correlated with angiogenesis (15) and was inverseley correlated with apoptosis (16).

The platelet-derived growth factor (PDGF) is a potent mitogen for many different cell types. PDGF plays a central 
role in regulating cell proliferation, chemotaxis, and survival in normal cells as well as in various disease states such as cancer, atherosclerosis, and fibrotic disease (17). PDGF is composed of $\mathrm{A}, \mathrm{B}, \mathrm{C}$, and $\mathrm{D}$ polypeptide chains that form the homodimers PDGF-AA, BB, CC, and DD and the heterodimer PDGF-AB. Its biological activities are linked to two tyrosine kinase receptors, PDGF- $\alpha$ and $-\beta$ receptors (PDGF-R $\alpha$ and PDGF-RB)(18). The PDGF/PDGF-R-pathway is summarized in Fig. 1. Increased expression of PDGF and its receptors has been demonstrated in various malignant human tumors such as prostate, ovarian, and non-small cell lung cancer (reviewed in ref. 17). Previous studies have demonstrated that PDGFs and their receptors are not only involved in human cancers through a paracrine but also an autocrine stimulation of tumor cell growth (19). In addition to its directly mitogen effect on tumor cells, PDGF also nourishes the tumor proliferation by stimulating the angiogenetic process directly and indirectly $(20,21)$. PDGF enhances migration and proliferation of endothelial cells, smooth muscle cells and pericytes $(19,22)$.

The recognised importance of tumor-induced angiogenesis has stimulated the development of agents that are able to interfere with the molecules involved in this process (4). In recent years, different compounds that inhibit PDGF-receptor kinases have been developed. Imatinib (Gleevec, also known as STI571; Novartis Pharma, Basel, Switzerland) is a protein-tyrosine kinase inhibitor of the 2-phenylaminopyrimidine class that was developed initially for its selectivity against the BCR-ABL fusion protein present in nearly all patients with chronic myeloid leukemia (23). In addition, it was found that Imatinib also inhibits the kinase activity of the PDGF-R $\alpha$-[and -(ß)] and c-Kit-receptor (24). Imatinib is in clinical use for the treatment of BCR-ABL positive chronic myeloid leukaemia and c-Kit-positive gastrointestinal stromal tumors. In an animal model for dermatofibrosarcoma protuberans, Imatinib was shown to inhibit tumor growth by blocking PDGF-R and induction of apoptosis (25).

To date, the reports on the activity of PDGF in HNSCC as well as the effect of a targeted therapy directed at inhibiting PDGF-R activity in HNSCC are rare.

In the present study, we sought a) to incipiently certify the overexpression of PDGF in HSNCC and b) to determine the effects of an inhibition of the PDGF-R on the expression and secretion of PDGF in head and neck cancer cell lines and whether this affected the expression and secretion of VEGF in vitro by hypothesising there is crosslinking between the PDGF/PDGF-R and VEGF/VEGF-R pathway systems (shown in Fig. 2).

\section{Materials and methods}

Characterization of PDGF in patients with primary head and neck squamous cell carcinoma and in head and neck cancer cells. For an introductive analysis of serum levels of PDGF $(-A B)$, we investigated the sera from patients of the Department of Otorhinolaryngology, Head and Neck Surgery, University Hospital Mannheim with histologically new diagnosed head and neck squamous cell carcinomas $(n=88,14$ females, 74 males, mean age 53) as well as from healthy normal controls $(n=46)$. The peripheral venous blood samples were processed
$24 \mathrm{~h}$ after collection. The serum was separated from the cellular components by centrifugation at $1000 \mathrm{~g}$ for $15 \mathrm{~min}$ and aliquoted. The sera samples were collected in sterile cryotubes and stored at $-80^{\circ} \mathrm{C}$ until usage. Then, the PDGF concentrations in the sera were determined by using the quantitative immunoassay technique of ELISA as described below. Furthermore, we performed RT-PCR for PDGF-A/-B to confirm the expression of PDGF in HNSCC using 4 different UM-SCC cell lines which were well-described human HNSCC cell lines (RT-PCR and cell cultures performed as described below). All studies were approved by the Ethics Committee of the Faculty of Medicine Mannheim, University of Heidelberg, Germany. Informed consent was obtained from all participants.

Cell culture. The 4 different UM-SCC cell lines were welldescribed human HNSCC cell lines obtained from T. Carey (The University of Michigan, Ann Arbor, MI, USA). Cell cultures were carried out in Falcon petri dishes at $37^{\circ} \mathrm{C}$ in a $5 \% \mathrm{CO}_{2}$ fully humidified atmosphere using Dulbecco's modified minimum essential medium (DMEM)(Fisher Scientific Co., Pittsburgh, PA, USA) supplemented with $10 \%$ fetal calf serum (FCS) and antibiotics [Life Technologies, Inc. (Gibco BRL), Gainthersburg, MD, USA]. Imatinib (Gleevec) was kindly provided by Novartis Pharma, Basel, Switzerland. It was stored at room temperature and diluted in sterile water as necessary at the time of use. The HNSCC cells were incubated with different concentrations of Imatinib $(0.1 ; 0.2 ; 0.4 ; 0.6 ; 0.8 ; 1.0 \mu \mathrm{mol} / 1)$ for 24 and $72 \mathrm{~h}$, then the supernatants were collected in sterile test tubes and stored at $-20^{\circ} \mathrm{C}$ until usage. Cells were harvested for PCR analysis at $-80^{\circ} \mathrm{C}$.

ELISA for VEGF/PDGF (-AB). VEGF concentrations were determined by ELISA technique (R\&D Systems, Wiesbaden, Germany). The system used a solid-phase monoclonal antibody and an enzyme-linked polyclonal antibody raised against recombinant VEGF165. The specificity of anti-human VEGF antibodies used in the ELISA kit were examined by sodium dodecylsulphate polyacrylamide gel electrophoresis (SDSPAGE) followed by Western blotting (14.15). According to the manufacturer's directions, each ELISA assay measured $100 \mu 1$ of supernatant. All analyses and calibrations were carried out in duplicate. The calibrations on each microtiter plate included recombinant human VEGF standards provided in the kit. Optical density was determined using a micro-plate reader at a wavelength of $450 \mathrm{~nm}$. Wavelength correction was set to $540 \mathrm{~nm}$ and concentrations were reported as $\mathrm{pg} / \mathrm{ml}$. The coefficient of variation of inter-assay determinations reported by the manufacturer varied from $6.2 \%$ to $8.8 \%$ when VEGF concentrations ranged between 50 and $1000 \mathrm{pg} / \mathrm{ml}$. The PDGF (-AB) -ELISA technique (R\&D Systems, Wiesbaden, Germany) was conducted in the same manner as that for VEGF-ELISA. The solid-phase monoclonal antibody was in that case a monoclonal antibody specific for PDGF-BB, the enzyme-linked polyclonal antibody was specific for PDGF-AA.

$R T-P C R$. A multiplex approach was used for the determination of levels of the gene transcription of VEGF. The RT-PCR step was conducted with a commercial Multiplex-PCR Kit 


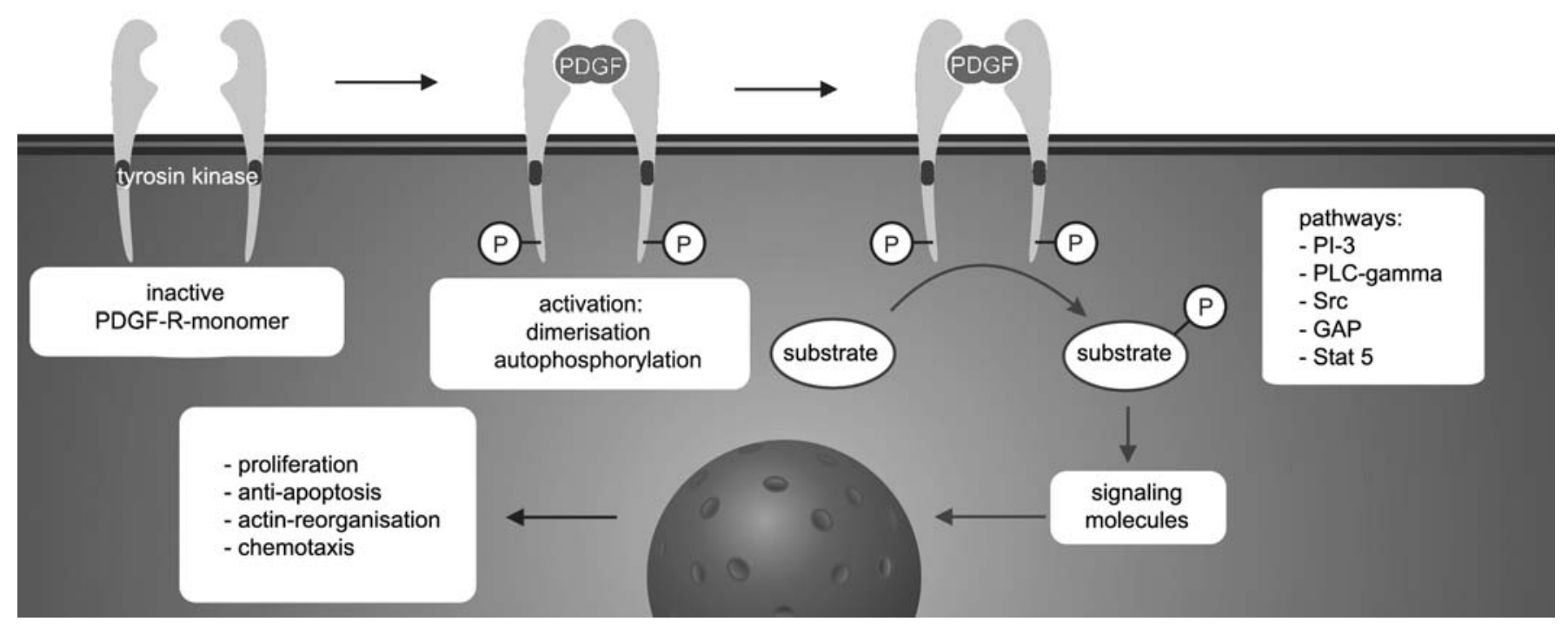

Figure 1. PDGF/PDGF-R pathway: PDGF binds to its receptor providing intrinsic tyrosine kinase activity which results in receptor activation by dimerisation and autophosphorylation. Hereby the receptor is able to induce signaling molecules that conduct to the different biological effects of PDGF.

(VEGF-MPCR Kit Set-1; Maxim Biotech, Inc., Rockville MD). RT-MPCR provides a method to detect multiple gene expression by amplifying all the genes under the same conditions, the kit used detects the expression of human GAPDH, VEGF189, 165, 121 and VEGF receptors flt-1 and flk-1 genes. Reverse transcription and first strand synthesis was performed using 1-2 $\mu \mathrm{g}$ of mRNA and $50 \mu \mathrm{M}$ Oligo (dT) as recommended by the manufacturer. The RT process was performed by incubating the RT mixture at $37^{\circ} \mathrm{C}$ for $60 \mathrm{~min}$ and terminated by heating RT mixture at $95^{\circ} \mathrm{C}$ for $10 \mathrm{~min}$ and then chilling on ice. PCR was then conducted with Taq DNA polymerase using $5 \mu \mathrm{l}$ cDNA derived from the first strand synthesis plus $5 \mu \mathrm{l}$ of hVEGF1G MPCR primers, the cDNA amplification was performed with 32 cycles of $94,58-60^{\circ} \mathrm{C}$. The resulting DNA was run on a $2 \%$ agarose gel and stained with ethidium bromide, and the image was captured with a Gel-Doc (Bio-Rad) imager. The image was analyzed, and samples were normalized to the expression of GAPDH. The product yields fragments 750 (GAPDH), 554 (flt-1), 408 (flk-1), 306 (VEGF189), 234 (VEGF165) and 104 (VEGF121) bp long. For the RT-PCR of PDGF-A and PDGF-B, reverse transcription was conducted in the same manner as that for VEGF. The PCR step was conducted with the Human PDGFB-/Human PDGF-A PCR Kit from R\&D Systems (Wiesbaden, Germany) that contains primers for PDGF-A/PDGF-B according to the manufacturer's instructions and performed analogous to the VEGF-PCR described previously. The cDNA products yield was 285 bp (PDGF-A) and 296 bp (PDGF-B) long.

Statistical analysis. For statistical analysis, PDGF (-AB) serum distributions between the HNSCC cancer patients and normal healthy controls were compared using the Wilcoxon 2-sample test. Differences in serum PDGF (-AB) levels were analysed depending on the main clinicopathological features of the patients (tumor localization, histological grading, T-stage and lymph node status, staging). Serum levels of PDGF (-AB) were expressed as a mean $\pm \mathrm{SD}$. All data were subjected to the Kruskal-Wallis test (Chi-square approximation). A p-value $\leq 0.05$ was considered statistically significant.

\section{Results}

Characterization of PDGF in patients with primary head and neck squamous cell carcinoma and in head and neck cancer cells. Initially we investigated the serum levels of circulating PDGF (-AB) in HNSCC patients and the correlation with the clinicopathological status of the tumor (tumor localization, histological grading, T-stage and lymph node status, staging) by using the quantitative immunoassay technique of ELISA. The serum levels of PDGF (-AB) were found to be significantly higher in the HNSCC patient group than those in the control group (mean HNSCC group $5945.28 \mathrm{pg} / \mathrm{ml}$; mean control group $1708.52 \mathrm{pg} / \mathrm{ml} ; \mathrm{p}=<0.001$; shown in Fig. 3). On the contrary, we could not find any significant correlation to the clinicopathological stage of the tumor (tumor localization $\mathrm{p}=0.4038$, histological grading $\mathrm{p}=0.1064$, lymph node status $\mathrm{p}=0.4770$, staging $\mathrm{p}=0.7663$; data not shown). RT-PCR for PDGF-A mRNA exhibited PDGF-A expression in all 4 HNSCC cell lines (Fig. 4). Among the head and neck cancer cell lines, a relatively intense signal of the band was noted in UM-SCC 14C cells. This cell line was chosen for further study. RT-PCR for PDGF-B mRNA showed no expression of PDGF-B in all HNSCC cell lines (data not shown).

Effect of Imatinib on HNSCC cell lines. To determine the effect of Imatinib on UM-SCC 14C cells, we added different concentrations of Imatinib (0.1-1.0 $\mu \mathrm{mol} / \mathrm{l})$. To quantitate PDGF as well as VEGF secretion to the supernatant of HNSCC cell lines treated with medium (control) or medium containing Imatinib, ELISA was performed after 48 and $72 \mathrm{~h}$. 


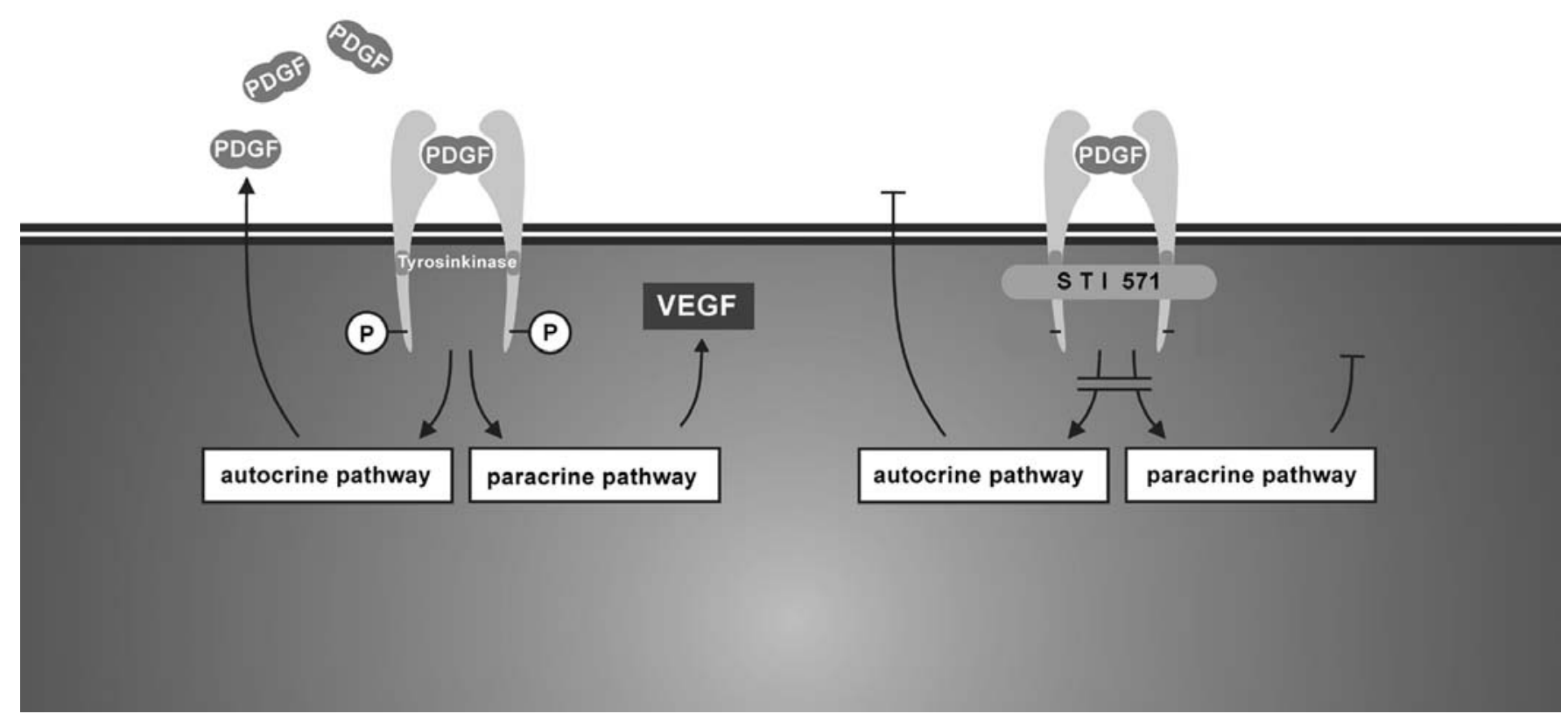

Figure 2. Hypothetical interaction between the PDGF/PDGF-R and VEGF pathway with potential effect of PDGF-R inhibition by Imatinib (STI 571).

PDGF(-AB) serum levels

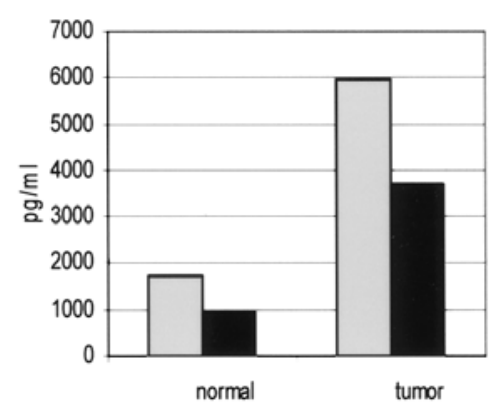

Figure 3. Comparison of PDGF (-AB) serum levels of HNSCC tumor patients (tumor) and healthy controls (normal). Serum levels of PDGF (-AB) were found to be significantly higher in the HNSCC patient group than those in the control group.

PDGF levels were significantly decreased by the Imatinib treatment at all concentrations with a maximal reduction at $0.6 \mu \mathrm{mol} / \mathrm{l}$ for $24 \mathrm{~h}(66.533 \mathrm{pg} / \mathrm{ml} ; 24 \mathrm{~h}$ negative control $145.072 \mathrm{pg} / \mathrm{ml})$ and at $0.2 \mu \mathrm{mol} / 1$ for $72 \mathrm{~h}(328.405 \mathrm{pg} / \mathrm{ml} ; 72 \mathrm{~h}$ negative control $568.461 \mathrm{pg} / \mathrm{ml})$. These results are shown in Fig. 5.

VEGF levels were also significantly decreased by the Imatinib treatment at all concentrations with a maximal reduction at $0.6 \mu \mathrm{mol} / 1$ for $24 \mathrm{~h}(966.612 \mathrm{pg} / \mathrm{ml} ; 24 \mathrm{~h}$ negative control $2068.00 \mathrm{pg} / \mathrm{ml}$ ) and at $0.4 \mu \mathrm{mol} / 1$ for $72 \mathrm{~h}$ (5103.42 pg/ml; $72 \mathrm{~h}$ negative control $8691.63 \mathrm{pg} / \mathrm{ml}$ ). These results are summarised in Fig. 6. Endogenous PDGF-A/ PDGF-B as well as VEGF expression in UM-SCC 14C cells treated with medium (control) or medium containing Imatinib for 24 and $72 \mathrm{~h}$ was measured by RT-PCR. The expression of PDGF-A was stable and not influencend by the Imatinib treatment after 24 and $72 \mathrm{~h}$, the expression of PDGF-B

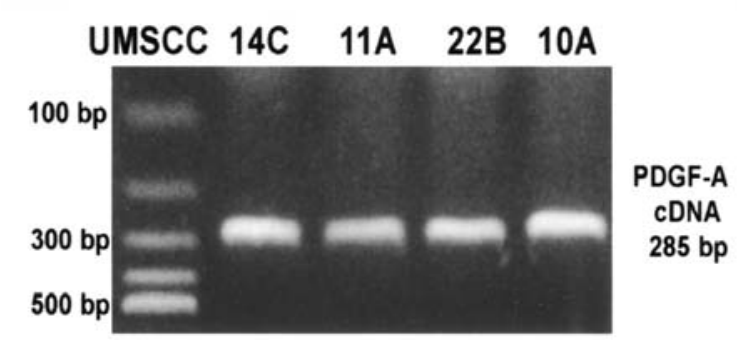

Figure 4. RT-PCR for PDGF-A mRNA exhibited PDGF-A expression in all 4 UMSCC cell lines.

remained absent at all times. On the contrary, we observed a reduction of VEGF expression after $24 \mathrm{~h}$ as well as after $72 \mathrm{~h}$. In agreement with the results of secretion measurements, we noted a maximal decrease of expression at an Imatinib concentration of $0.6 \mu \mathrm{mol} / 1$ for $24 \mathrm{~h}$ and at $0.2 / 0.4 \mu \mathrm{mol} / 1$ for 72 h. Representative results are shown in Fig. 7.

\section{Discussion}

The inhibition of angiogenesis of malignant tumors has become an important strategy to be considered in novel approaches to cancer therapy. It is widely accepted that an increase in the tumor cell population must be preceded by an increase in microvessels supplying the neoplasm $(4,6)$. It was demonstrated that the supernatant from HNSCC cell lines induced an angiogenic response in vivo (26). Dray et al demonstrated a strong correlation between high microvessel counts and recurrent or metastatic disease in HNSCC. Their data also suggested that microvessel counts were associated not only with an increased incidence of early recurrence or 


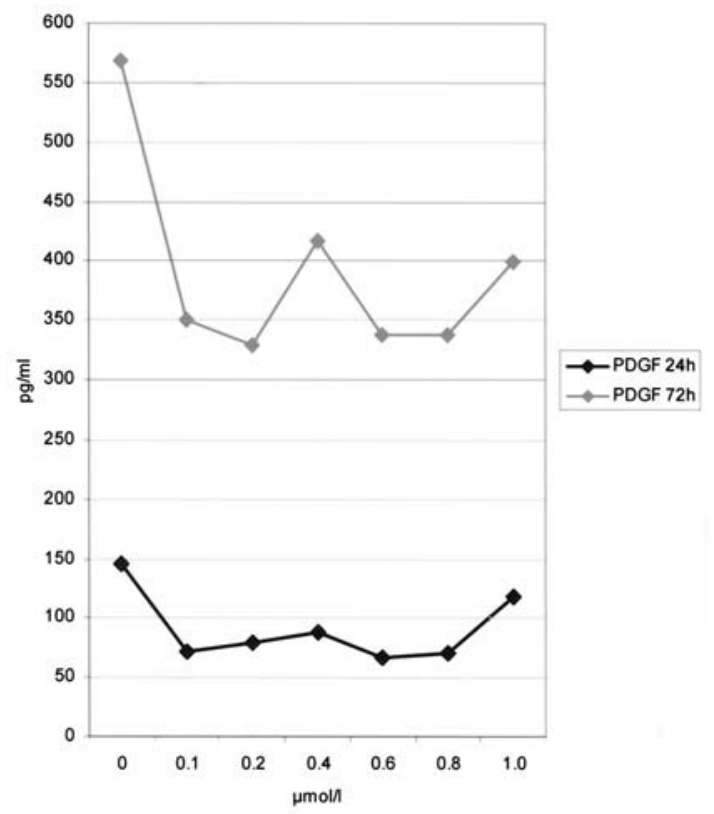

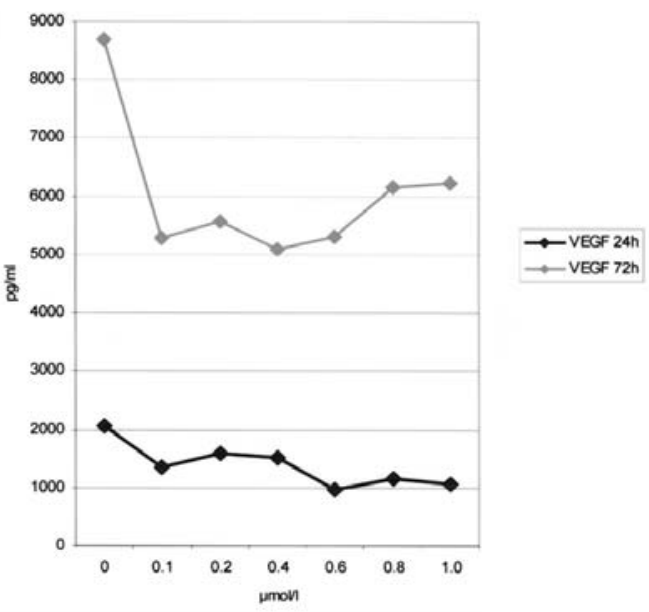

Figure 6. VEGF concentrations in supernatant of UMSCC cells after $24 \mathrm{~h}$ and $72 \mathrm{~h}$ incubation with different concentrations of Imatinib $(0.1-1.0 \mu \mathrm{mol} / \mathrm{l}$; ELISA).

Figure 5. PDGF (-AB) concentrations in supernatant of UMSCC cells after $24 \mathrm{~h}$ and $72 \mathrm{~h}$ incubation with different concentrations of Imatinib (0.1-1.0 $\mu \mathrm{mol} / 1$; ELISA).

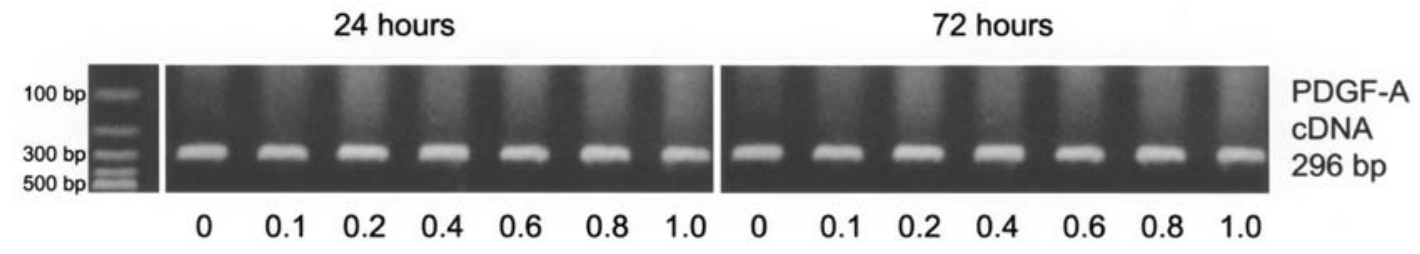

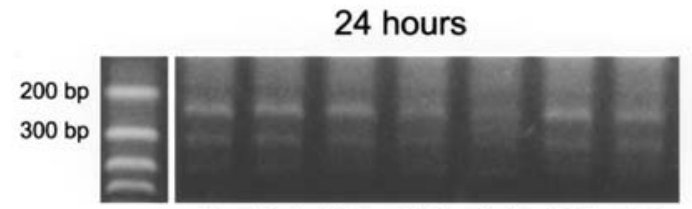

$\begin{array}{lllllll}0 & 0.1 & 0.2 & 0.4 & 0.6 & 0.8 & 1.0\end{array}$

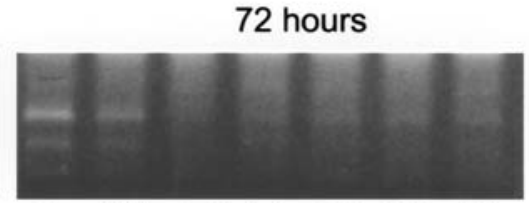

VEGF

$-189306 \mathrm{bp}$

$-165234 \mathrm{bp}$

Figure 7. RT-PCR after 24 and $72 \mathrm{~h}$ of incubation with different concentrations of Imatinib (0.1-1.0 $\mu$ mol/1). Expression of PDGF-A was not influenced by Imatinib, Expression of PDGF-B remained absent (data not shown). Expression of VEGF was reduced with a maximal decrease contrary to the maximal decrease of secretion at $0.6 \mu \mathrm{mol} / 1$ for $24 \mathrm{~h}$ and at $0.2 / 0.4 \mu \mathrm{mol} / 1$ for $72 \mathrm{~h}$.

metastasis, but also with more aggressive forms of recurrent or metastatic disease (27).

One of the major angiogenic stimulators is the VEGF, a directly acting endothelial cell mitogen. A significant body of evidence is accumulating that favours the notion that VEGF plays an important role in the development of solid tumors, such as head and neck cancer (9). VEGF expression has been detected in a large number of malignant human tumors including HNSCC (11-13).

PDGF is another crucial growth factor for tumor cell growth, angiogenesis and survival of the tumor (17). PDGF was shown to be a potent angiogenetic factor in vitro and in vivo $(20,21,28,29)$. As VEGF and PDGF are recognised contributors to the angiogenetic process and as recent studies hinted at an interaction between these mitogens (30-33), we suggested that these factors may be co-regulated and this prompted us to investigate whether there is a correlation between the PDGF/PDGF-R axis and the activity of VEGF in HNSCC cells.

As reports on the expression of PDGF in human malignancies are uncommon, we carried out a preliminary analysis on the state of PDGF in patients with HNSCC and in HNSCC cell lines. Our results demonstrated elevated serum levels of PDGF (-AB) in the majority of patients with primary head and neck cancer compared to healthy controls, although there was no correlation with the clinicopathological stage of the 
tumor, suggesting there is no interrelation between the role of PDGF and the tumor measurements. Our findings are in line with previous studies that reported on elevated PDGF-AB serum levels in patients suffering from HNSCC as well as the expression of PDGF-AB protein in native tumor tissue and its maintained secretion in the derived HNSCC cultures (34-36). Likewise, other investigations found no correlation between PDGF expression levels in tumor derived cells and clinicopathological factors $(36,37)$.

The elevation of PDGF in HNSCC is also represented on mRNA level, where we showed PDGF-A expression in all 4 HNSCC cell lines. In contrast, we did not observe an expression of PDGF-B in any of the investigated UM-SCC cell lines. Chang et al found that the expression of PDGF was much higher and more frequent in head and neck tumor tissue compared to paired normal tissue (38). Li et al reported on up-regulated expression of PDGF in oral squamous cell carcinomas (39). However, neither study specified between the PDGF-A or -B chain. Aebersold et al described the expression of PDGF-B in oropharyngeal cancers and proved by immunoreactivity that the presence of PDGF-B was confined to the tumor cells themselves, whereas PDGF-A was often expressed to a marked degree by vascular endothelial cells in the stroma (37). However, Worden et al described in accordance with our findings, an expression of PDGF-A in HNSCC tissue (40). Collectively, these observations and our findings support the notion that HNSCC cells provide complex expression patterns of PDGF. The evaluation of the expression of PDGF chains and their respective receptors in different human malignancies provided distinct findings for expression patterns in various tumor entities (reviewed in ref. 17). However, the knowledge of the expression patterns of PDGF chains and their respective receptors in HNSCC remains incomplete.

Imatinib (Gleevec) is a protein-tyrosine kinase inhibitor that was also found to inhibit the kinase activity of the PDGF-R $[-\alpha$ and $-(B)](24)$, and it was shown that Imatinib inhibits tumor growth by blocking PDGF-R and the induction of apoptosis (25). In this present study, we hypothesized that Imatinib may inhibit HNSCC cell growth, angiogenesis and survival of the tumor via the inhibition of an PDGF/PDGF-R autocrine growth pathway as well as inhibition of a VEGF paracrine loop. Our obtained results showed that an inhibition of PDGF-R in HNSCC by Imatinib leads to a reduced secretion of PDGF (-AB) protein. These results also suggest that HNSCC cells exhibit an autocrine loop in the pathway of the PDGF/PDGF-R system. However, these results could not be shown on the mRNA level, whereas, the inhibition of PDGF-R in HNSCC cells caused the reduction of secretion as well as the expression of VEGF. To our knowledge, this is the first study demonstrating these effects in HNSCC cell lines. Comparable results were recently published for other tumor entities, it was reported that a PDGF-R inhibition by Imatinib inhibited the growth of neuroblastoma and leads to the inhibition of VEGF expression (41). In PDGF-R expressing immortalized ovarian cancer cells, PDGF potently induced VEGF secretion, while Imatinib reduced PDGF stimulated VEGF production to basal state (42), another study demonstrated decreased PDGF-R and VEGF expression after the use of Imatinib in non-small cell lung cancer (NSCLC) xenografts (43).
In summary, the present study confirmed the crucial role of PDGF in HNSCC growth and strongly suggests a correlation between the PDGF/PDGF-R and VEGF/VEGF-R pathway networks in HNSCC. Although further studies must be undertaken for a more complete understanding of this interaction, a targeting therapy for the inhibition of PDGF-R tyrosine phosphorylation by Imatinib may be a promising strategy for future tumor therapy by autocrine and paracrine inhibition of tumor growth and angiogenesis, presumably through simultaneous PDGF and VEGF down-regulation.

\section{Acknowledgements}

We gratefully thank Petra Prohaska for excellent technical support and Novartis Pharma (Basel, Switzerland) for kindly providing Imatinib (Gleevec). We would also like to thank Herbert Palmer for his great assistance with manuscript preparation. This work was supported by the German Foundation Tumorforschung Kopf/Hals.

\section{References}

1. Shibuya K, Mathers CD, Boschi-Pinto C, Lopez AD and Murray CJ: Global and regional estimates of cancer mortality and incidence by site: II. Results for the global burden of disease 2000. BMC Cancer 2: 37, 2002.

2. Ries LAG, Eisner MP, Kosary CL, Hankey BF, Miller BA, Clegg L, et al: SEER Cancer Statistics Review, 1975-2002. National Cancer Institute, Bethesda, MD, 2005.

3. Dimery IW and Hong WK: Overview of combined modality therapies for head and neck cancer. J Natl Cancer Inst 85: 95$111,1993$.

4. Folkman J: Angiogenesis in cancer, vascular, rheumatoid and other disease. Nat Med 1: 27-31, 1995.

5. Riedel F, Götte K, Schwalb J, Bergler W and Hörmann K: Coexpression of VEGF and bFGF is associated with increased vascular density in head and neck carcinomas. Laryngorhinootologie 79: 730-735, 2000.

6. Risau W: Mechanisms of angiogenesis. Nature 386: 671-674, 1997.

7. Folkman J and Klagsbrun M: Angiogenetic Factors. Science 235: 442-447, 1987.

8. Dvorak HF, Brown LF, Detmar M and Dvorak HM: Vascular permeability factor/vascular endothelial growth factor, microvascular hyperpermeability and angiogenesis. Am J Pathol 146: 1029-1039, 1995

9. Ferrara N: The role of vascular endothelial growth factor in pathological angiogenesis. Breast Cancer Res Treat 36: 127-137, 1995.

10. Zhang HT, Craft P, Scott PA, Ziche M, Weich HA, Harris AL and Bicknell R: Enhancement of tumor growth and vascular density by transfection of vascular endothelial cell growth factor into MCF-7 human breast carcinoma cells. Natl Cancer Inst 87: 213-219, 1995.

11. Eisma RJ, Spiro JD and Kreutzer DL: Vascular endothelial growth factor expression in head and neck squamous cell carcinoma. Am J Surg 174: 513-517, 1997.

12. Mineta H, Miura K, Ogino T, Takebayashi S, Misawa K, Ueda Y, Suzuki I, Dictor M, Borg A and Wennerberg J: Prognostic value of vascular endothelial growth factor in head and neck squamous cell carcinomas. Br J Cancer 83: 775-781, 2000.

13. Salven P, Heikkilä P, Anttonen A, Kajanti M and Joensuu H: Vascular endothelial growth factor in squamous cell head and neck carcinoma: expression and prognostic significance. Mod Pathol 10: 1128-1133, 1997

14. Riedel F, Götte K, Schwalb J, Wirtz H, Bergler W and Hörmann K: Serum levels of vascular endothelial growth factor in patients with head and neck cancer. Eur Arch Otorhinolaryngol 257: 332-336, 2000.

15. Riedel F, Götte K, Schwalb J, Schäfer C and Hörmann K: Expression of vascular endothelial growth factor correlates with angiogenesis and p53 mutations in head and neck squamous cell carcinoma. Acta Otolaryngol 120: 105-111, 2000. 
16. Riedel F, Götte K, Bergler W and Hörmann K: Inverse correlation of angiogenic and apoptotic markers in squamous cell carcinoma of the head and neck. Oncol Rep 8: 471-476, 2001.

17. Heldin $\mathrm{CH}$ and Westermark B: Mechanism of action and in vivo role of platelet-derived growth factor. Physiol Rev 79: 1283-1316, 1999.

18. Betsholtz C, Karlsson L and Lindahl P: Developmental roles of platelet-derived growth factors. Bioessays 23: 494-507, 2001.

19. $\mathrm{Yu}$ J, Ustach $\mathrm{C}$ and Kim HR: Platelet-derived growth factor signaling and human cancer. J Biochem Mol Biol 36: 49-59, 2003.

20. Risau W, Drexler H, Mironov V, Smits A, Siegbahn A, Funa K and Heldin $\mathrm{CH}$ : Platelet-derived growth factor is angiogenic in vivo. Growth Factors 7: 261-266, 1992.

21. Pietras K, Ostman A, Sjöquist M, Buchdunger E, Reed RK, Heldin $\mathrm{CH}$ and Rubin K: Inhibition of platelet-derived growth factor receptors reduces interstitial hypertension and increases transcapillary transport in tumors. Cancer Res 61: 2929-2934, 2001.

22. Thommen R, Humar R, Misevic G, Pepper MS, Hahn AW, John $\mathrm{M}$ and Battegay EJ: PDGF-BB increases endothelial migration on cord movements during angiogenesis in vitro. $\mathrm{J}$ Cell Biochem 64: 403-413, 1997.

23. Druker BJ and Lydon NB: Lessons learned from the development of an Abl tyrosine kinase inhibitor for chronic myelogenous leukemia (Perspective). J Clin Invest 105: 3-7, 2000.

24. Buchdunger E, Cioffi CL, Law N, Stover D, Ohno-Jones S, Druker BJ and Lydon NB: Abl protein-tyrosine kinase inhibitor STI571 inhibits in vitro signal transduction mediated by c-Kit and platelet-derived growth factor receptors. J Pharmacol Exp Ther 295: 139-145, 2000.

25. Sjoblom T, Shimizu A, O'Brien KP, Pietras K, Dal Cin P, Buchdunger E, Dumanski JP, Ostman A and Heldin CH: Growth inhibition of dermatofibrosarcoma protuberans tumors by the platelet-derived growth factor receptor antagonist STI571 through induction of apoptosis. Cancer Res 61: 5778-5783, 2001.

26. Petruzelli GJ, Snyderman CH, Johnson JT and Myers EN: Angiogenesis induced by head and neck squamous cell carcinoma xenografts in the chick embryo chorioallantioc membrane model. Ann Otol Rhinol Laryngol 102: 212-221, 1993.

27. Dray TG, Hardin NJ and Sofferman RA: Angiogenesis as a prognostic marker in early head and neck cancer. Ann Otol Rhinol Laryngol 104: 724-729, 1995.

28. Sato N, Beitz JG, Kato J, Yamamoto M, Clark JW, Calabresi P, Raymond A and Frackelton AR Jr: Platelet-derived growth factor indirectly stimulates angiogenesis in vitro. Am J Pathol 142: 1119-1130, 1993

29. Lindahl P, Bostrom H, Karlsson L, Hellstrom M, Kalen M and Betsholtz C: Role of platelet-derived growth factors in angiogenesis and alveogenesis. Curr Top Pathol 93: 27-33, 1999.

30. Wang D, Huang HJ, Kazlauskas A and Cavenee WK: Induction of vascular endothelial growth factor expression in endothelial cells by platelet-derived growth factor through the activation of phosphatidylinositol 3-kinase. Cancer Res 59: 1464-1472, 1999.
31. Jo N, Mailhos C, Ju M, Cheung E, Bradley J, Nishijima K, Robinson GS, Adamis AP and Shima DT: Inhibition of plateletderived growth factor B signaling enhances the efficacy of antivascular endothelial growth factor therapy in multiple models of ocular neovascularization. Am J Pathol 168: 2036-2053, 2006.

32. Ball SG, Shuttleworth CA and Kielty CM: Vascular endothelial growth factor can signal through platelet-derived growth factor receptors. J Cell Biol 177: 489-500, 2007.

33. Shen J, Vil MD, Zhang H, Tonra JR, Rong LL, Damoci C, Prewett M, Deevi DS, Kearney J, Surguladze D, Jimenez X, Iacolina M, Bassi R, ZZhou K, Balderes P, Mangalampalli VR, Loizos N, Ludwig DL and Zhu Z: An antibody directed against PDGF receptor beta enhances the antitumor and the antiangiogenic activities of an anti-VEGF receptor 2 antibody. Biochem Biophys Res Commun 357: 1142-1147, 2007.

34. Zhang JZ, Maruyama K, Ono I and Kaneko F: Production and secretion of platelet-derived growth factor $\mathrm{AB}$ by cultured human keratinocytes: regulatory effects of phorbol 12- myristate 13-acetate, etretinate, 1,25-dihydroxyvitamin D3, and several cytokines. J Dermatol 22: 305-309, 1995.

35. Gleich LL, Srivastava L and Gluckman JL: Plasma plateletderived growth factor: preliminary study of a potential marker in head and neck cancer. Ann Otol Rhinol Laryngol 105: 710-712, 1996.

36. Ninck S, Reisser C, Dyckhoff G, Helmke B, Bauer H and Herold-Mende C: Expression profiles of angiogenic growth factors in squamous cell carcinomas of the head and neck. Int J Cancer 106: 33-34, 2003.

37. Aebersold DM, Froehlich SC, Jonczy M, Beer KT, Laissue J, Greiner RH and Djonov V: Expression of transforming growth factor-alpha, epidermal growth factor receptor and plateletderived growth factors A and B in oropharyngeal cancers treated by curative radiation therapy. Radiother Oncol 63: 275-283, 2002.

38. Chang JT, Chen IH, Liao CT, Wang HM, Hsu YM, Hung KF, Lin CJ, Hsieh LL and Cheng AJ: A reverse transcription comparative real-time PCR method for quantitative detection of angiogenic growth factors in head and neck cancer patients. Clin Biochem 35: 591-596, 2002.

39. Li C, Shintani S, Terakado N, Klosek SK, Ishikawa T, Nakashiro K and Hamakawa H: Microvessel density and expression of vascular endothelial growth factor, basic fibroblast growth factor, and platelet-derived endothelial growth factor in oral squamous cell carcinomas. Int J Oral Maxillofac Surg 34: 559-565, 2005.

40. Worden B, Yang XP, Lee TL, Bagain L, Yeh NT, Cohen JG, Van Waes C and Chen Z: Hepatocyte growth factor/scatter factor differentially regulates expression of proangiogenic factors through Egr-1 in head and neck squamous cell carcinoma. Cancer Res 65: 7071-7080, 2005.

41. Beppu K, Jaboine J, Merchant MS, Mackall CL and Thiele CJ: Effect of imatinib mesylate on neuroblastoma tumorigenesis and vascular endothelial growth factor expression. J Natl Cancer Inst 96: 46-55, 2004.

42. Matei D, Kelich S, Cao L, Menning N, Emerson RE, Rao J, Jeng $\mathrm{MH}$ and Sledge GW: PDGF BB induces VEGF secretion in ovarian cancer. Cancer Biol Ther 6: 1951-1959, 2007.

43. Vlahovic G, Ponce AM, Rabbani Z, Salahuddin FK, Zgonjanin L, Spasojevic I, Vujaskovic Z and Dewhirst MW: Treatment with imatinib improves drug delivery and efficacy in NSCLC xenografts. Br J Cancer 97: 735-740, 2007. 